\title{
A Candida albicans 37 kDa polypeptide with homology to the laminin receptor is a component of the translational machinery
}

\author{
Mercedes Montero, Antonio Marcilla, Rafael Sentandreu \\ and Eulogio Valentin
}

Author for correspondence: Eulogio Valentin. Tel: +34638642 99. Fax: +3463864682.

e-mail: eulogio.valentin@uv.es

Sección de Microbiología, Facultad de Farmacia, Universidad de Valencia, Av. Vicente Andrés Estellés $s / n, 46100$-Burjassot, Valencia, Spain

\begin{abstract}
A CDNA encoding a $37 \mathrm{kDa}$ protein was isolated from an expression library using antibodies raised against mycelial cell walls from Candida albicans. The $37 \mathrm{kDa}$ protein has over $60 \%$ sequence identity with the $37 \mathrm{kDa}$ lamininbinding protein (LBP) from humans and over $80 \%$ identity with the Yst proteins of Saccharomyces cerevisiae. The $C$. albicans protein was named CaYst1. It was found in membrane and ribosome fractions but surprisingly, was not found in cell walls. Unlike the human LBP, CaYst1p does not bind laminin. These data indicate that CaYst1p is not a cell-surface receptor for laminin as has been proposed for the human LBP. Instead, like the S. cerevisiae Yst proteins, it appears to be a ribosomal protein. This conclusion is supported by the finding that CaYST1-CDNA complements the lethal phenotype linked to the disruption of both YST genes in S. cerevisiae.
\end{abstract}

Keywords: Candida albicans, Saccharomyces cerevisiae, yst mutations, laminin receptor, ribosomal protein

\section{INTRODUCTION}

Candida albicans is an opportunistic fungus which can cause either septicaemic or mucosal infections in humans (Odds, 1988). The organism is capable of reproducing by budding (yeast cells) or by producing germ tubes (mycelial cells) depending upon environmental factors; this morphological transition has been associated with pathogenicity (Calderone \& Braun, 1991; Odds, 1988; Sentandreu et al., 1993). Because the cell wall of $C$. albicans maintains the characteristic shape for each growth form and is the site of the initial interactions between the organism and its environment, various studies have focused on the biosynthesis and function of this structure (Gozalbo et al., 1994; Sentandreu et al., 1993). The role that glycoproteinaceous components of the cell wall play in morphogenesis has also been studied (Gozalbo et al., 1994; Sentandreu et al., 1993). By immunoscreening of expression libraries from Saccharomyces cerevisiae, C. albicans or Yarrowia lipolytica, genes encoding cell-wall proteins of $S$. cerevisiae (Moukadiri et al., 1997) and Y. lipolytica (Ramón et al.,

Abbreviation: LBP, laminin-binding protein.

The EMBL accession number for the nucleotide sequence reported in this paper is $Y 11434$.
1996) have been cloned; however, genes of cytosolic proteins, rather than cell-wall proteins, have been cloned in the case of C. albicans (Eroles et al., 1995, 1997; Sentandreu et al., 1995).

Among the cell-surface proteins described from $C$. albicans, a $37 \mathrm{kDa}$ laminin-binding protein (LBP) has been reported (López-Ribot et al., 1994, 1996). Additionally, hypothetical LBPs have been described in mammals, Arabidopsis thaliana, Urechis caupo and $S$. cerevisiae, although each was associated with polysome fractions of cells (Auth \& Brawerman, 1992; Demianova et al., 1996; García-Hernández et al., 1994; Rosenthal \& Worderman, 1995). In the present study, we report the isolation of a cDNA from $C$. albicans that encodes a protein closely related (over $80 \%$ similarity) to the ribosomal Yst proteins of S. cerevisiae (Demianova et al., 1996). This protein, designated CaYst1, exhibits over $60 \%$ identity with a mammalian LBP, although in our experimental conditions no specific binding to laminin was observed. CaYst1p was found in ribosomes, membranes and cytosol fractions of C. albicans and complemented $y s t$ mutations in S. cerevisiae.

\section{METHODS}

Strains, media, growth conditions and transformations. $C$. albicans ATCC 26555 (serotype A) was employed in this 
study. The organism was propagated as a yeast or mycelium in Lee's medium (Lee et al., 1975), as described previously (Casanova et al., 1989; López-Ribot et al., 1991). S. cerevisiae 8-3D [MATa/MAT $\alpha \rho^{+}$ade2/ade2 can1/can1 his3/his3 ura3/ura3 leu2/leu2 trp1/trp1 YST1/yst1D1(::URA3) YST2/yst $2 \Delta 1(:: H I S 3)]$ was used in genetic complementation studies; media used for cultivating yeast were complete YPD medium (Sherman, 1991) and minimal medium $[0.7 \%(\mathrm{w} / \mathrm{v})$ yeast nitrogen base without amino acids, $2 \%(\mathrm{w} / \mathrm{v})$ glucose] supplemented with the appropriate nutrients in amounts as specified by Sherman (1991). Transformed and untransformed S. cerevisiae $8-3 \mathrm{D}$ were sporulated in solid SPO media $[1 \%$ $(\mathrm{w} / \mathrm{v})$ potassium acetate, $0.1 \%(\mathrm{w} / \mathrm{v})$ yeast extract, $0.05 \%$ $(\mathrm{w} / \mathrm{v})$ glucose, $2 \%(\mathrm{w} / \mathrm{v})$ agar] plus the appropriate nutrients in $25 \%(\mathrm{v} / \mathrm{v})$ of the amounts used in synthetic complete media. Escherichia coli $\mathrm{DH} 5 \alpha \quad\left[\mathrm{F}^{-} \phi 80 \mathrm{~d}\right.$ lacZ $\triangle \mathrm{M} 15$ recA1 endA1 gyrA96 thi-1 hsdR17 $\left(\mathrm{r}_{\mathrm{k}}^{-} \mathrm{m}_{\mathrm{k}}^{+}\right)$, supE44 relA deoR $\Delta($ lacZYA-argF $)$ U169] was used routinely for molecular cloning and plasmid amplification. E. coli NM522 [supE thi $\Delta$ (lac-proAB $) \Delta h s d 5\left(\mathrm{r}^{-} \mathrm{m}^{-}\right) \mathrm{F}^{\prime}$ proAB lacl $\left.^{\mathrm{q}} \mathrm{Z} \Delta \mathrm{M} 15\right]$ was used as a host strain for the phage $\lambda$ ExCell (Pharmacia) and amplified by standard procedures (Sambrook et al., 1989). E. coli was transformed as described by Hanahan (1983). The transformation of intact yeast cells was performed as described by Ito et al. (1983); plasmids were rescued from yeast by transformation of $E$. coli with yeast DNA extracted according to Hoffman \& Winston (1987).

cDNA library construction, screening and DNA manipulations. A C. albicans cDNA library consisting of $1.16 \times 10^{4}$ clones, with a mean insert of $1.5 \mathrm{~kb}$, was generated from protoplasts regenerating at $37^{\circ} \mathrm{C}$ (as mycelia) in phage expression vector $\lambda E x C e l l$. Protoplasts were obtained and regenerated as described by Elorza et al. (1983). For mRNA isolation and cDNA synthesis, the mRNA Purification Kit and cDNA Synthesis Kit, both from Pharmacia, were used, respectively, according to the manufacturer's instructions. cDNAs obtained were subsequently linked to EcoRI-NotI adapters (Pharmacia) prior to their insertion into EcoRIdigested $\lambda$ ExCell. Rabbit antibodies raised against mycelial cell walls from C. albicans ATCC 26555 were used to screen the cDNA library, as described previously (Ramón et al., 1996; Sentandreu et al., 1995). Those phage demonstrating enrichment on subsequent screening were isolated and the cDNA inserts rescued by PCA, using universal forward and reverse pUC/M13 primers (Promega). The PCR products were digested with EcoRI and then cloned in the plasmid vector pUC18.

Standard DNA manipulation techniques were carried out as described by Sambrook et al. (1989). DNA probes for Southern and Northern blot analysis were labelled by random primed incorporation of digoxigenin-labelled deoxyuridine-triphosphate (DIG-labelled DNA) using the DIG DNA Labeling Kit (Boehringer Mannheim) according to the manufacturer's instructions.

Southern hybridization analysis. Chromosomal DNA from C. albicans and S. cerevisiae X-2180-1A, hybridization conditions and detection of DIG-labelled nucleic acids were performed as described by Ramón et al. (1996).

RNA isolation and Northern hybridization. Total RNA isolation from $C$. albicans and $S$. cerevisiae, and Northern hybridization were carried out as previously described (Ramón et al., 1996), except that disodium 3-(4-methoxyspiro\{1,2-dioxetane-3,2'-(5'-chloro)tricyclo[3.3.1.1 $1^{3,7}$ ] decan $\}-4-y 1$ ) phenyl phosphate (CSPD from Boehringer Mannheim) was used as a substrate. RNA concen- trations were determined by measuring absorbance $\left(A_{260}\right)$ in a Gene Quant II RNA/DNA calculator spectrophotometer (Pharmacia).

DNA sequencing. DNA sequencing was performed on both strands by the dideoxy chain-termination method (Sanger $e t$ al., 1977). Sequencing reactions were carried out with the Auto Read Sequencing Kit (Pharmacia) and cycle sequencing with fmol Cycle Sequencing System (Promega), in both cases according to the specifications of the suppliers. Sequencing was carried out with an ALF DNA Sequencer (Pharmacia Biotech).

SDSPAGE and Western blot analysis. Different subcellular fractions (cytosol, membranes and ribosomes) and SDS, $\beta$ mercaptoethanol or Zymolyase $20 \mathrm{~T}$ extracts from C. albicans cell walls were obtained as previously described (Casanova et al., 1989, 1992; Elorza et al., 1988; Raué et al., 1991) and run on SDS $-10 \%(\mathrm{w} / \mathrm{v})$ polyacrylamide gels as described by Laemmli (1970). For Western blot analysis, proteins were electrophoretically transferred from SDS-PAGE gels onto nitrocellulose filters according to Towbin et al. (1979). Filters were probed with rabbit antibodies against the epitopes expressed by $\lambda$ ExCell-CaYST1 at a final concentration of $1: 100$, followed by goat anti-rabbit IgG conjugated to horseradish peroxidase (Bio-Rad). Antiserum binding was visualized by using the ECL (enhanced chemiluminescence) fluorescent labelling kit (Western Blotting Protocols; Amersham) following the manufacturer's instructions.

Preparation of specific antibodies. To obtain specific antibodies against proteins encoded by CaYST1-cDNA, a purified $\lambda$ ExCell-CaYST1-cDNA clone was plated at a density sufficient to produce confluent plaques in $150 \mathrm{~mm}$ plates. After incubation of plates for $4 \mathrm{~h}$ at $42^{\circ} \mathrm{C}$, they were overlaid with nitrocellulose membranes as previously described (Ramón et al., 1996). The membranes were then removed and blocked with $3 \%$ BSA in TBS $[20 \mathrm{mM}$ Tris $/ \mathrm{HCl}(\mathrm{pH} 7 \cdot 5), 150 \mathrm{mM}$ $\mathrm{NaCl}$ ] for $30 \mathrm{~min}$ at $37^{\circ} \mathrm{C}$ without shaking and then $30 \mathrm{~min}$ at room temperature with gentle shaking. Following blocking, the membranes were incubated overnight at room temperature with rabbit antibodies against $C$. albicans cell walls preadsorbed on an E. coli Y1090 extract $\left(1 \mathrm{mg} \mathrm{ml}^{-1}\right.$ final concentration). The membranes were then washed four times for $10 \mathrm{~min}$ at room temperature in TTBS $[20 \mathrm{mM}$ Tris $/ \mathrm{HCl}$ ( $\mathrm{pH} 7.5$ ), $150 \mathrm{mM} \mathrm{NaCl}$ plus $0.05 \%$ Tween 20], once in TBS and stripped with $0.1 \mathrm{M}$ glycine $(\mathrm{pH} 2.8)$ for $20 \mathrm{~min}$ at room temperature. The glycine solution was then equilibrated with $3 \mathrm{M}$ Tris $/ \mathrm{HCl}(\mathrm{pH} 8.5)$, collected and stored at $-20^{\circ} \mathrm{C}$. This solution contained specific antibodies against epitopes expressed by $\lambda$ ExCell-CaYST1 (CaYst1p-Abs).

Plasmid construction and $S$. cerevisiae yst complementation. Plasmid pCME22 was made by cloning CaYST1-cDNA into EcoRI-digested pUC18. pCME23 was constructed by cloning a $1.0 \mathrm{~kb}$ EcoRI fragment (blunt-ended prior to ligation) from pCME22 into the HincII site of pUC19 and the orientation of inserts checked. YEpCaYST1-ACT and YEpCaYST1-GAL were constructed by cloning the $X b a \mathrm{I}-P s t \mathrm{I}$ fragment from pCME23 into the XbaI-PstI sites of YEplac181ACT (RandezGil et al., 1995) and YEplac112GAL (I. Moukadiri, unpublished data) so that CaYST1 was under control of the ACT promoter and GAL promoter, respectively.

To examine the effect of CaYST1-cDNA on complementation of $S$. cerevisiae yst mutation, $S$. cerevisiae 8-3D was transformed with YEpCaYST1-ACT or YEpCaYST1-GAL. Transformants prototrophic for leucine or tryptophan were sporulated and tetrads dissected by micromanipulation. 
1

1 ATA GCG GCC GCG CAT ATA ATA GAG AAT ATG TCA TTA

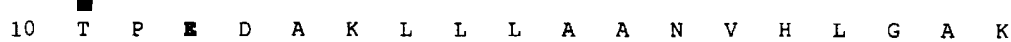

55 ACT CCA GAA GAC GCT AAA TTG TTA TTA GCT GCC AAC GTC CAT TTG GGT GCT AAG

$\begin{array}{lllllllllllllllllllllll}28 & N & V & Q & V & H & N & K & P & Y & V & Y & K & T & R & P & D & G & M\end{array}$

109 AAC GTT CAA GTT CAC AAC AAA CCA TAT GTT TAC AAA ACC AGA CCA GAT GGT ATG

$\begin{array}{llllllllllllllllllll}46 & N & I & I & N & I & G & K & T & W & \mathbf{E} & K & I & V & I & A & A & R & I\end{array}$

163 AAC ATC ATC AAC ATT GGT AAA ACT TGG GAA AAA ATT GTT TTG GCT GCC AGA ATT

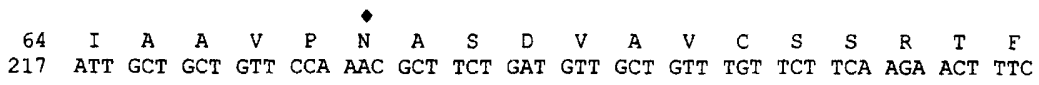

\begin{tabular}{llllllllllllllllllll}
82 & $G$ & $Q$ & $R$ & $A$ & V & L & K & F & A & A & H & T & G & A & T & A & I & A \\
\hline
\end{tabular}

271 GGT CAA AGA GCT GTT TTG AAA TTT GCT GCT CAC ACT GGT GCT ACT GCC ATT GCT

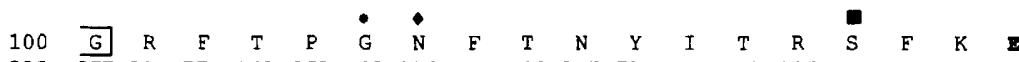

325 GGT AGA TTC ACT CCA GGT AAC TTT ACC AAT TAT ATC ACT CGT TCA TTC AAA GAA

$\begin{array}{lllllllllllllllllll}118 & P & R & L & V & V & V & T & D & P & R & T & D & A & Q & A & I & K & \mathbb{B}\end{array}$

379 CCA AGA TTA GTT GTT GTT ACT GAC CCA AGA ACC GAT GCT CAA GCC ATC AAA GAA

$\begin{array}{llllllllllllllllllll}136 & S & S & Y & V & N & I & P & V & I & A & L & T & D & M & Q & S & P & S\end{array}$

433 TCA TCT TAT GTT AAC ATT CCA GTT ATT GCC TTG ACT GAC ATG CAG TCT CCA TCT

$\begin{array}{lllllllllllllllllll}154 & \mathbf{z} & \mathrm{Y} & \mathrm{V} & \mathrm{D} & \mathrm{V} & \mathrm{A} & \mathrm{I} & \mathrm{P} & \mathrm{C} & \mathrm{N} & \mathrm{N} & \mathrm{K} & \mathrm{G} & \mathrm{K} & \mathrm{H} & \mathrm{S} & \mathrm{I} & \mathrm{G}\end{array}$

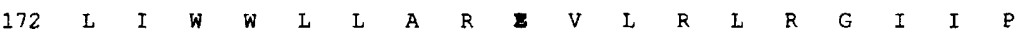

541 TTA ATC TGG TGG TTG CTT GCT AGA GAA GTC TTG AGA TTA AGA GGT ATT ATC CCA

$\begin{array}{lllllllllllllllllll}190 & D & R & T & T & \mathbf{E} & W & S & V & M & P & D & L & Y & F & Y & R & D & P\end{array}$

595 GAC AGA ACT ACC GAA TGG TCA GTT ATG CCA GAT TTG TAC TTC TAC AGA GAC CCA

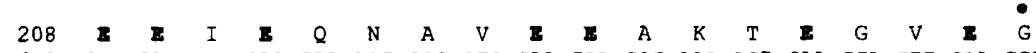

649 GAA GAA ATT GAA CAA AAT GCC GTC GAA GAA GCT AAA ACT GAA GGA GTT GAA GGA

$\begin{array}{lllllllllllllllllll}226 & A & P & V & A & \mathbf{E} & A & \mathbf{E} & T & \mathbf{E} & \text { W } & T & G & \mathbf{E} & T & \mathbf{E} & \mathrm{D} & \mathrm{V} & \mathrm{D}\end{array}$

703 GCT CCA GTT GCT GAA GCT GAA ACC GAA TGG ACT GGT GAA ACT GAA GAT GTT GAT

$\begin{array}{lllllllllllllllll}244 & W & A & D & S & G & A & T & P & S & C & \text { * }\end{array}$

757 TGG GCT GAT TCT GGT GCT ACC CCC AGC TGC TGA AGA TGC TGC TGC TTC TAA CTG

811 GTA AAC ACT GAA ATC TAC CAA TAA GAA GTA GAA GTA GAA GTA GAA GAA GAA ACA

865 ATA ACA ACA ATA ACA ACC AAA ATA AAA AAA AGG TTT AAT GAT GTA TAT TAT CGA

919 TAA GGA GAA AGA AGA GAT TTT CTT TTT TAA TAA TGA GGA TGC CAT TTT ATA CAA

973 ATC CAA AAT TGT AAT TAA GAA AGA TTA ATA AAT ATA AAA TAT ATA TAT ATA AGT

1027 AAA AAA AAA AAA AAA A

\begin{abstract}
Fig. 1. Nucleotide and predicted amino acid sequences of a cDNA clone encoding CaYst1p. Numbering of bases starts at the first nucleotide and amino acids at the first methionine as potential start site of the ORF. Putative polyadenylation signals are underlined. The stop codon is marked with an asterisk and the putative $\mathrm{N}$-glycosylation sites by a diamond. Squares indicate possible serine/threonine phosphorylation sites and circles putative myristoylation sites. Glutamic residues are in bold letters. A theoretical transmembrane region is boxed.
\end{abstract}

Spores were germinated on minimal medium supplemented with amino acids and analysed by examination for prototrophy for uracil and histidine.

\section{RESULTS}

\section{CaYST1-CDNA cloning}

With the aim of identifying wall proteins of $C$. albicans mycelial cells, rabbit polyclonal antibodies raised against mycelial cell walls were used for immunoscreening an oligo-dT-primed $\lambda$ ExCell library obtained from C. albicans protoplasts regenerating as mycelium. Approximately $1.2 \times 10^{6}$ recombinant phage were immunoscreened and after three rounds we identified 35 potentially positive clones. cDNA inserts were amplified by PCR using pUC/M13 forward and reverse primers and DIG-labelled. All 35 PCR-amplified DNA inserts cross-hybridized amongst themselves when analysed by Southern blot analysis. The clone with the largest cDNA fragment (approx. $1.0 \mathrm{~kb}$ ) was chosen and subcloned in pUC18. The recombinant plasmid was named pCME22. The 1042 bp cDNA sequence (Fig. 1) contained a single ORF of 762 nucleotides beginning with an ATG at position 28-30, followed by an in-frame TGA stop codon at position $787-789$. In the $3^{\prime}$ region two possible polyadenylation consensus signals (AATAAA) were found at 95 and $209 \mathrm{bp}$ downstream of the stop codon; a poly (A) region was also present at the $3^{\prime}$ end. These findings established the orientation of the clone with respect to mRNA transcription and suggested that the entire coding sequence is contained within pCME22. The predicted amino acid sequence from this ORF was 253 residues long with a calculated molecular mass of $27.8 \mathrm{kDa}$ and a theoretical isoelectric point of 4.89 .

Further computer analysis revealed the following features (Fig. 1): the protein sequence contained two possible $N$-glycosylation sites at positions 69 and 106 and four putative serine/threonine phosphorylation sites, three of them for casein kinase II (positions 10, 40 and 151) and one for protein kinase $C$ (position 114). The relatively high abundance and the distribution pattern of glutamic acid residues proved distinctive: 19 residues were evenly distributed throughout the 253 amino acid sequence; 12 residues were present in the last 50 amino acids at the carboxyl terminus of the molecule. Hydropathy analysis (Kyte \& Doolittle, 1982) of the deduced amino acid sequence showed a hydrophilic protein containing some weak hydrophobic regions. One of these hydrophobic regions contained a potential transmembrane region (Rao \& Argo, 1986) of 16 amino 


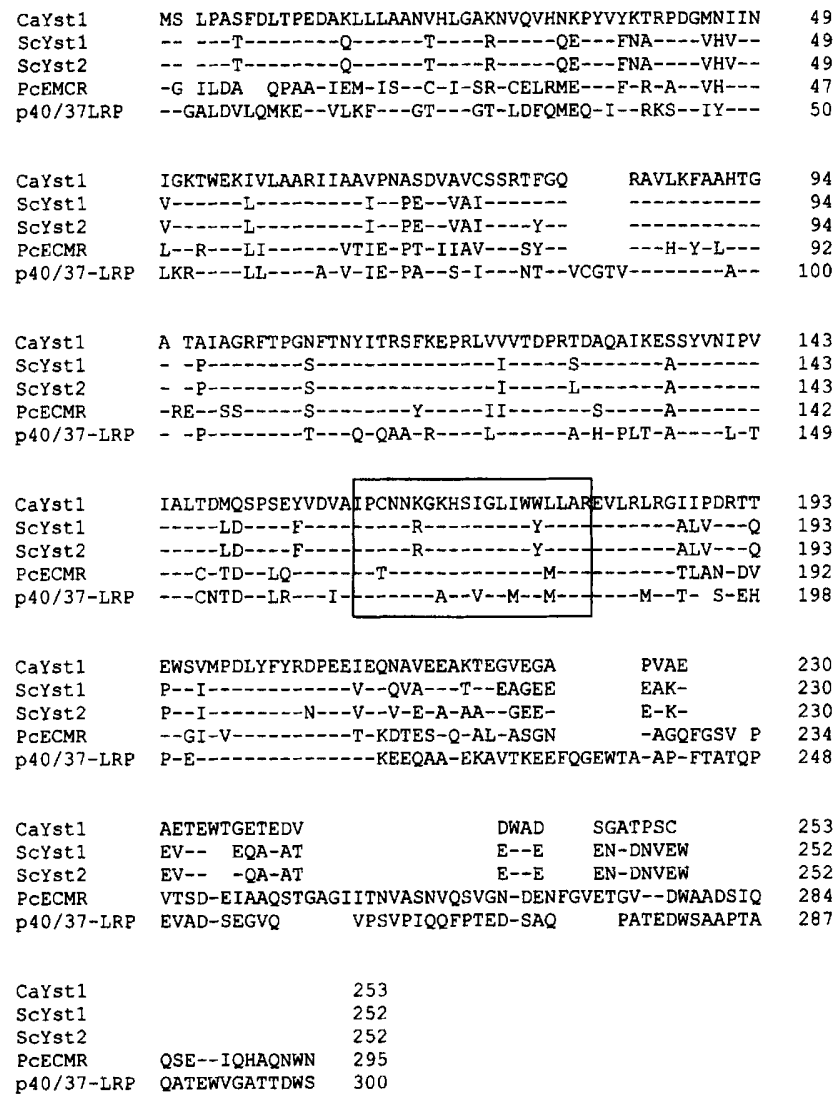

Fig. 2. Alignments of CaYst1p amino acid sequence with $Y s t 1$ and $Y$ st2 from $S$. cerevisiae ( $\mathrm{ScYst}$ ), $P$. carinii extracellular matrix protein laminin receptor (PCECMR) and human p40/37-LRP (laminin receptor protein). Identities with CaYst1p are denoted by dashes; blank spaces represent gaps introduced to maximize alignment. The boxed region corresponds to peptide $G$ homologues (see text for details).

acids located at position 85-100 (Fig. 1). Two putative myristoylation sites at amino acid positions 105 and 225 may indicate membrane anchoring and/or proteinprotein interaction (McIlhinney, 1990).

A comparison of the predicted amino acid sequence with those in the public databases using the BLAST program (Altschul et al., 1990) revealed significant similarity (over $80 \%$ ) with the ribosomal Yst1 and Yst2 proteins of S. cerevisiae (Demianova et al., 1996), the Pneumocystis carinii extracellular matrix protein (over $70 \%$ ) that binds laminin and fibronectin in vitro (Narasimhan et al., 1994) and human LBP (over 60\%) (Yow et al., 1988) (Fig. 2). The homology included a region similar to peptide G, responsible for laminin binding (Castronovo et al., 1991). Since the highest similarity was found with the Yst proteins from S. cerevisiae we have named this protein $\mathrm{CaYst1}$ (Ca for C. albicans).

To gain an insight into the genomic organization of CaYST1, Southern blot hybridization was performed using chromosomal DNA of C. albicans, digested with EcoRI. The CaYST1-cDNA from DIG-labelled pCME22 hybridized with chromosomal DNA, con-

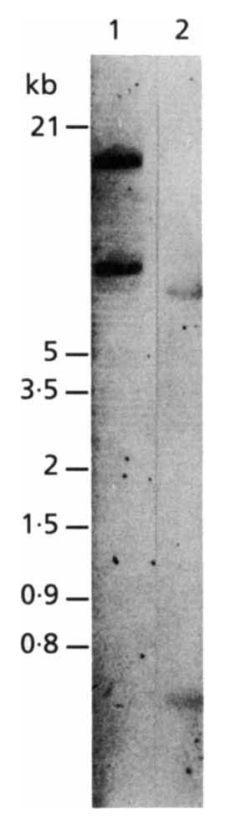

Fig. 3. Southern blot of C. albicans (lane 1) and S. cerevisiae (lane 2) genomic DNA. DNAs from C. albicans and S. cerevisiae were digested with EcoRI, electrophoresed on an agarose gel and transferred to nylon membranes. The blot was hybridized with a DIG-labelled CDNA probe from a pCME22 clone. Molecular mass markers ( $\lambda$ DNA digested with ECORI and HindIII) are shown on the left.

firming that this cDNA clone was derived from a nuclear gene. The fact that two signals were detected (Fig. 3) suggests the presence of two copies of CaYST1 since no EcoRI sites were found in the ORF. When chromosomal DNA from $S$. cerevisiae digested with EcoRI was analysed, two weak signals were also observed in Southern blot using DIG-labelled CaYST1 as a probe (Fig. 3), confirming the similarity between CaYST1 and ScYST genes.

To study the transcription of CaYST1, Northern blots of RNA from mycelial and yeast cells of C. albicans were performed using the DIG-labelled cDNA from pCME22 as a probe. Two transcripts of 1.2 and $1.1 \mathrm{~kb}$ from both yeast and mycelium were observed, although both transcripts were more abundant in mycelial forms of C. albicans (Fig. 4). These results are in agreement with those obtained by Southern analysis.

\section{Cellular distribution of CaYst1p in C. albicans}

To determine the cellular localization of CaYst1p, specific antibodies against epitopes expressed by $\lambda$ ExCell-CaYST1 were obtained as described in Methods. Yeast and mycelial cells of C. albicans were broken and the resulting suspension fractionated into cytosol, a particulate membrane preparation and cell walls. The latter were extracted with SDS, $\beta$ mercaptoethanol and Zymolyase 20T. SDS-PAGE and Western blots using specific antibodies revealed the presence of a single band of approximately $37 \mathrm{kDa}$ in the 


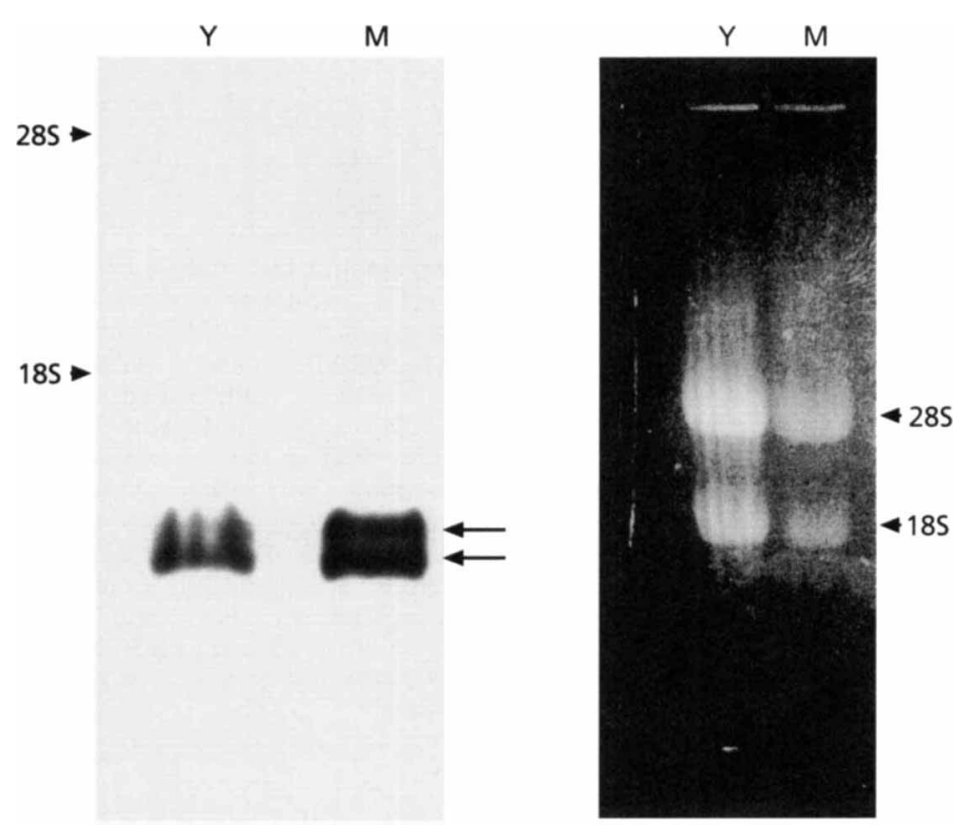

Fig. 4. Northern blot analysis of total $C$. albicans RNA isolated from cells growing as yeast $(\mathrm{Y})$ or mycelium (M). Total RNA was electrophoresed through an agarose/ formaldehyde gel and transferred to a nylon membrane. The blotted membrane was hybridized with a DIG-labelled CDNA probe from a PCME22 clone. The corresponding ethidium bromide-stained gel is shown on the right and positions of rRNAs (18S and 285 ) are indicated by arrowheads. Arrows mark the two transcripts.

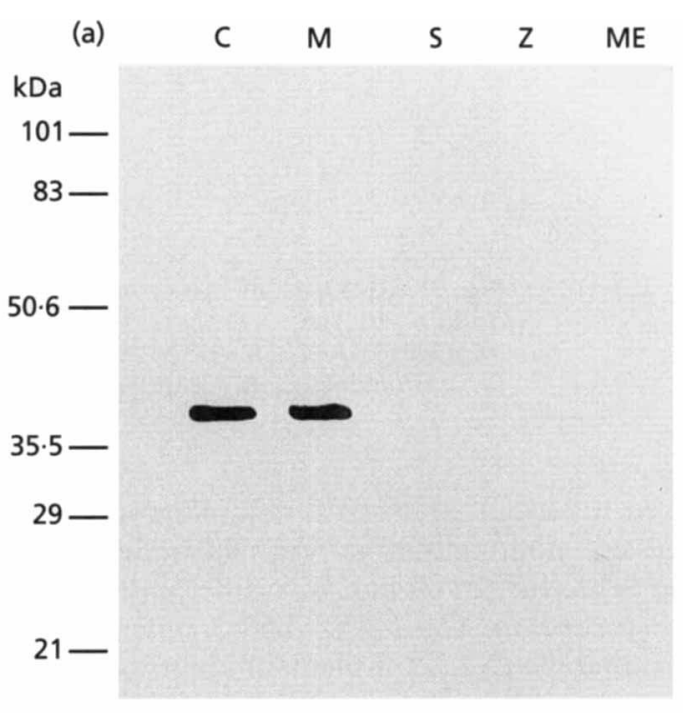

(b)

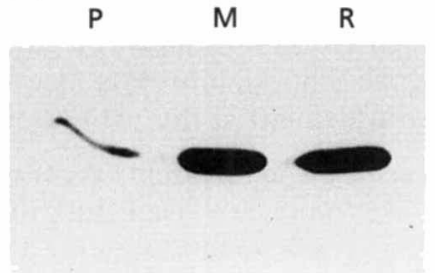

Fig. 5. Western blot of different cell fractions from C. albicans mycelial cells. Proteins $(5 \mu \mathrm{g}$ from each fraction) were electrophoresed on SDS-10\% polyacrylamide gels, transferred to nitrocellulose membranes and probed with specific antibodies against CaYstip. (a) $C$, cytosol; $M$, particulate membrane fraction; S, SDS-released cell-wall material; Z, Zymolyase-20Treleased cell-wall material; ME, $\beta$-mercaptoethanol-released cell-wall material. Molecular mass markers are shown on the left. (b) Distribution of CaYst1p in post-ribosomal supernatant $(P)$, membrane $(M)$ and ribosomal $(R)$ fractions. The results obtained with $C$. albicans yeast cells were similar. cytosol and particulate membrane fractions (Fig. 5a). However, no specific bands were detected in the cellwall fractions released by the various treatments. In $S$. cerevisiae, Yst proteins have been shown to be ribosomeassociated. To determine whether CaYst1p was also localized to ribosomes, a ribosomal fraction of $C$. albicans was obtained and analysed by SDS-PAGE, followed by immunoblot with specific antibodies. As shown in Fig. 5(b), CaYst1p is localized in membranes, ribosomes and, to a lesser extent, in the cytosol (postribosomal supernatant).

A $37 \mathrm{kDa}$ cell-surface protein of C. albicans that binds laminin and is recognized by an antibody preparation against the carboxyl-terminal laminin-binding domain of human laminin receptor (pAb 4160) (Castronovo et al., 1991) was identified from $\beta$-mercaptoethanol-extractable material from whole cells (López-Ribot et al., 1991, 1994). Because of this observation we then performed assays, as described by López-Ribot $e t$ al. (1994), to test whether CaYst1p was able to bind laminin in vitro. Neither the C. albicans native protein nor the fusion protein expressed in E. coli bound laminin under our experimental conditions (data not shown).

\section{CaYST1-cDNA complements yst mutations in S. cerevisiae}

To determine the function of $\mathrm{CaYst} 1 \mathrm{p}$, we next investigated whether CaYST1-cDNA could complement the lethal double yst mutation in S. cerevisiae (Demianova et al., 1996). For these experiments, the diploid strain $S$. cerevisiae 8-3D, heterozygous for YST1 and YST2, was transformed with YEpCaYST1-ACT, as described in Methods. Transformants were sporulated, tetrads dissected and grown in minimal medium supplemented with the appropriate nutrients, except leucine to select only those spores that contained YEpCaYST1-ACT. 


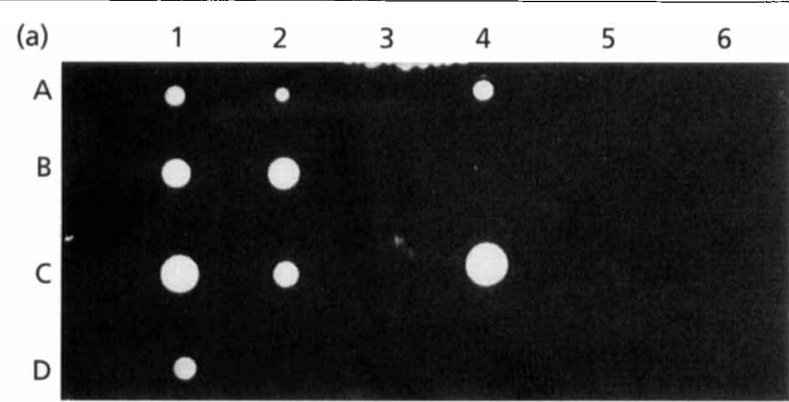

(b)

\begin{tabular}{|ccccccc|}
\hline \multirow{2}{*}{ Spore } & \multicolumn{5}{c|}{ Growth media } & Genotype \\
\cline { 2 - 5 } & -ura/-his & +ura/-his & - ura/this & +ura/this & \\
\hline 1A & - & + & - & + & YST1/yst2 \\
1B & - & - & + & + & yst1/YST2 \\
1C & - & - & - & + & YST1/YST2 \\
1D & + & + & + & + & yst1/yst2 \\
\hline
\end{tabular}

Fig. 6. Complementation analysis of the yst mutations. (a) S. cerevisiae 8-3D, a diploid strain heterozygous for YST1 and YST2, YST1/yst1- 1 1(::URA3) and YST2/yst2$\triangle 1(:: H I S 3)$, was transformed with YEPCaYST1-ACT, sporulated and tetrads dissected. Individual spores were grown on minimal medium with the appropriate nutrients except leucine. Numbers refer to different tetrads. (b) The four spores of tetrad 1 were analysed for uracil and histidine auxotrophies. Plus and minus designations in front of ura (uracil) and his (histidine) indicate the presence or absence of that nutrient. (a)

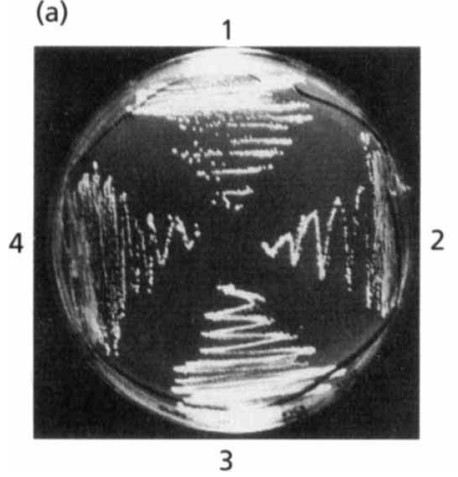

(b)

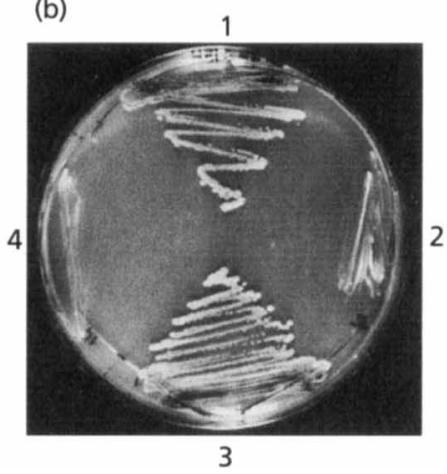

Fig. 7. Growth of $S$. cerevisiae yst1/yst2 double mutant containing the plasmid YEpCaYST1-ACT $(1,3)$ or YEpCaYST1-GAL $(2,4)$ on galactose $(a)$ or glucose $(b)$.

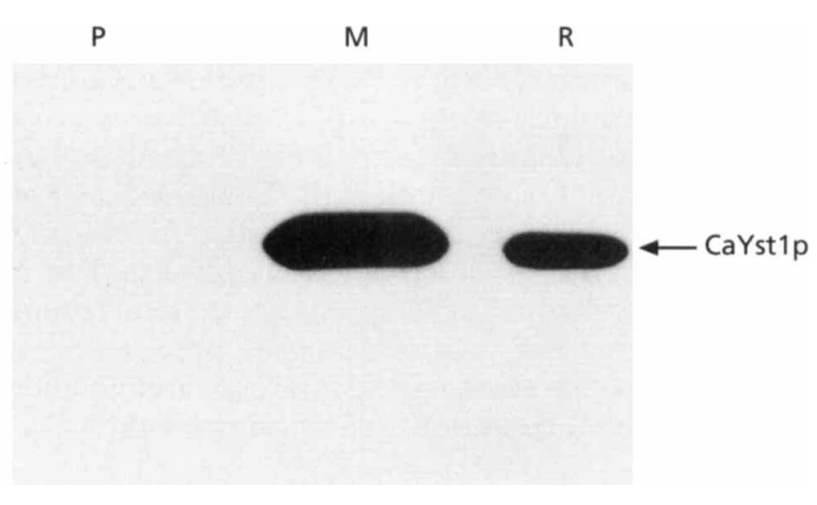

Fig. 8. Western blot of different cell fractions obtained from $S$. cerevisiae yst1/yst2 double mutant transformed with YEpCaYST1-ACT. The proteins $(5 \mu \mathrm{g}$ from each fraction) were processed as described in the legend to Fig. 5. P, post-ribosomal supernatant; $M$, membrane fraction; $R$, ribosomal fraction. CaYst1p is indicated by an arrow.

Representative results from the growth of individual spores are shown in Fig. 6(a). We assumed that the nonviable spores failed to harbour the plasmid YEpCaYST1-ACT. In tetrad 1, the four spores were analysed for uracil and histidine auxotrophies and the results are summarized in Fig. 6(b). Spore 1D was prototrophic for uracil and histidine, indicating that it was disrupted in YST1 and YST2 genes. This result showed that CaYST1 complemented the yst mutation in $S$. cerevisiae. Similar results were obtained when CaYST1 was overexpressed under an inducible promoter. The double yst mutant expressing CaYST1 under the GAL promoter could only grow on galactose, failing to grow on glucose (Fig. 7). This fact also demonstrated that CaYST1 complemented the yst mutation.

Because in S. cerevisiae Yst proteins are mainly localized in ribosomes, we next analysed the distribution of CaYst1p in this yeast. Membranes, ribosomes and cytosol were obtained from a double yst mutant transformed with YEpCaYST1-ACT and analysed by Western blot using CaYst1p-Abs. As in C. albicans, the p37 CaYst1p was localized mainly in membranes and ribosomes, and was not present in the cytosol (Fig. 8).

\section{DISCUSSION}

In the present study, we describe the isolation and characterization of a $C$. albicans cDNA encoding a protein of an apparent molecular mass of $37 \mathrm{kDa}$ that 
exhibits a high homology (over $80 \%$ similarity) to the recently described ribosomal Yst proteins of S. cerevisiae (Demianova et al., 1996). This protein also shares homology with $\mathrm{p} 40 / 37$ LBPs from a number of eukaryotic organisms (Fig. 2). Previous studies have suggested the association of homologous p $40 / 37$ LBPs with different cellular structures including the cytoskeleton in Hydra vulgaris (Keppel \& Schaller, 1991), ribosomes and also a soluble fraction in Arabidopsis thaliana and mammals (Auth \& Brawerman, 1992; García-Hernández et al., 1994). In fact, the Yst proteins are components of the $40 \mathrm{~S}$ ribosomal subunit in $S$. cerevisiae (Demianova et al., 1996). Similarly, CaYst1p localizes in the ribosomes of C. albicans, although it was also detected in membranes and in lesser amounts in the cytosol (Fig. 5b). Furthermore, the CaYST1 gene complements a yst mutation in S. cerevisiae when a heterozygous mutant is employed (the homozygous double mutant is inviable), indicating that the encoded protein exerts similar ribosomal functions.

Consistent with the previous observation that genes encoding yeast ribosomal proteins contain two virtually identical genes (Demianova et al., 1996; Rosenthal \& Worderman, 1995; Woolford \& Warner, 1991), two genes were detected by Southern analysis using the CaYST1-cDNA as a probe (Fig. 4). Two transcripts, differing by approximately $100-150 \mathrm{bp}$ were also detected by Northern blot, both hybridizing with the CaYST1-cDNA probe, indicating small differences in sequence and length, as occurs in S. cerevisiae (Demianova et al., 1996). Whether these two mRNAs are encoded by two or more genes remains unknown, although Southern blots suggest the presence of two. Interestingly, from enriched ribosomal fractions, no increase in the amount of CaYst1p was observed when compared to a total membranous fraction, where an intense band was detected by $\mathrm{CaYst} 1 \mathrm{p}-\mathrm{Abs}$ specific antibodies. The protein remained associated with the membrane preparation when these fractions were treated with agents that disorganize ribosomes (data not shown). Such results could suggest a cellular membrane localization, which is in agreement with a potential transmembrane domain found in the primary structure of the predicted amino acid sequence (Fig. 1).

The CaYST1 gene was cloned as result of an immunoscreening using antibodies generated against cell-wall components. While CaYst1p was detected associated with ribosomes, we were unable to detect it at the cell surface using different agents which have been extensively employed to analyse the proteins present in the C. albicans cell wall (Elorza et al., 1988; Marcilla et al., 1991). If CaYst1p $\mathrm{kDa}$ is only a cytoplasmic protein, then it must be antigenically related to cell-wall proteins to explain its initial selection from the expression library with antibodies against cell-wall proteins. Interestingly, recent reports have described LBPs from the cell surface of C. albicans germ tubes showing three components of 68, 62 and $60 \mathrm{kDa}$ (Bouchara et al., 1990), and, strikingly, a protein of $37 \mathrm{kDa}$ from C. albicans blastoconidia, which also cross-reacted with antibodies generated against the human laminin receptor (LópezRibot et al., 1994); whether these components are exclusively expressed in response to morphological changes remains unclear. Altogether, these results correlate with those described in mammals where the controversy is still unsolved (Mecham, 1991).

In this study laminin binding in vitro was not detected. $\mathrm{CaYst1p}$ expressed either in phage or in $E$. coli failed to bind laminin in vitro, as also occurred with different $C$. albicans extracts, even in conditions demonstrated to prevent protein loss (Glee et al., 1996) (data not shown). We might postulate the existence of proteins such as CaYst1p which possess a laminin-binding domain (peptide G) (Castronovo et al., 1991), but which are functionally not related to adhesins. The possible existence of proteins with more than one function should not be dismissed. In this context, several ribosomal proteins have been shown to have a second function apart from a ribosomal one (Wool, 1996). Future analysis should uncover whether this is also the case for CaYst1p.

A significant observation was the localization of CaYst1p when expressed in $S$. cerevisiae; it was not detected in the cytosol (Fig. 8), in contrast to the situation in C. albicans, suggesting in turn a different processing mechanism, as has also been described in the case of a cell-wall protein from Y. lipolytica (Ramón et al., 1996, 1997).

\section{ACKNOWLEDGEMENTS}

We gratefully acknowledge the helpful comments of Dr Steven $R$. Ellis and his generosity in providing us with the strain $S$. cerevisiae 8-3D. We thank M. D. Gómez-Lobo for the $C$. albicans cDNA library; M. C. Aguado for supplying rabbit anti-C. albicans mycelium cell-wall antibodies and Dr P. Sanz for the plasmid YEplacACT. M.M. is supported by a predoctoral fellowship from the Fundación Ramón Areces. This work was partially supported by grants from Dirección General de Investigación Científica y Técnica (PB93-0051), Fondo de Investigación Sanitaria de la Seguridad Social (95/1602), Spain and BMH4-CT96-0310, Brussels.

\section{REFERENCES}

Altschul, S. F., Gish, W., Miller, W., Myers, E. W. \& Lipman, D. J. (1990). Basic local alignment search tool. J Mol Biol 215, 403-410.

Auth, D. \& Brawerman, G. (1992). A 33-kDa polypeptide with homology to the laminin receptor: component of translation machinery. Proc Natl Acad Sci USA 89, 4368-4372.

Bouchara, J. P., Tronchin, G., Annaix, V., Robert, R. \& Senet, J. M. (1990). Laminin receptors on Candida albicans germ tubes. Infect Immun 58, 48-54.

Calderone, R. \& Braun, P. C. (1991). Adherence and receptor relationships of Candida albicans. Microbiol Rev 55, 1-20.

Casanova, M., Gil, M. L., Cardeñoso, L., Martínez, J.P. \& Sentandreu, R. (1989). Identification of wall-specific antigens synthesized during germ tube formation by Candida albicans. Infect Immun 57, 262-271.

Casanova, M., Lopez-Ribot, J. L., Martinez, J. P. \& Sentandreu, R. (1992). Characterization of cell wall proteins from yeast and 
mycelial cells of Candida albicans by labeling with biotin: comparison with other techniques. Infect Immun 60, 4898-4906.

Castronovo, V., Taraboletti, G. \& Sobel, E. M. (1991). Functional domains of the $67-\mathrm{kDa}$ laminin receptor precursor. J Biol Chem 266, 20440-20446.

Demianova, M., Formosa, T. G. \& Ellis, R. S. (1996). Yeast proteins related to the $\mathrm{p} 40 /$ laminin receptor precursor are essential components of the $40 \mathrm{~S}$ ribosomal subunit. J Biol Chem 271, 11383-11391.

Elorza, M. V., Rico, H., Gozalbo, D. \& Sentandreu, R. (1983). Cell wall composition and protoplast regeneration in Candida albicans. Antonie Leeuwenboek 49, 457-469.

Elorza, M. V., Marcilla, A. \& Sentandreu, R. (1988). Wall mannoproteins of the yeast and mycelial cells of Candida albicans: nature of the glycosidic bonds and polydispersity of their mannan moieties. J Gen Microbiol 134, 2393-2403.

Eroles, P., Sentandreu, M., Elorza, M. V. \& Sentandreu, R. (1995). Cloning of a DNA fragment encoding part of a $70 \mathrm{kDa}$ heat shock protein of Candida albicans. FEMS Microbiol Lett 128, 95-100.

Eroles, P., Sentandreu, M., Elorza, M. V. \& Sentandreu, R. (1997). The highly immunogenic enolase and Hsp70p are adventitious Candida albicans cell wall proteins. Microbiology 143, 313-320.

García-Hernández, M., Davis, E. \& Staswick, P. E. (1994). Arabidopsis p40 homologue: a novel acidic protein associated with the 40S subunit of ribosomes. J Biol Chem 269, 20744-20749.

Glee, P. M., Masuoka, J., Ozier, W. T. \& Hazen, K. C. (1996). Presence of multiple laminin- and fibronectin-binding proteins in cell wall extracts of Candida albicans : influence of dialysis. $J \mathrm{Med}$ Vet Mycol 34, 57-61.

Gozalbo, D., Elorza, M. V., Sanjuán, R., Marcilla, A., Valentín, E. \& Sentandreu, R. (1994). Critical steps in fungal cell wall synthesis: strategies for their inhibition. Pharmacol Ther 60, 337-345.

Hanahan, D. (1983). Studies on transformation of Escherichia coli with plasmids. J Mol Biol 166, 557-580.

Hoffman, C. S. \& Winston, F. (1987). A ten minute DNA preparation from yeast efficiently releases autonomous plasmid for transformation of Escherichia coli. Gene 57, 267-272.

Ito, H., Fukuda, Y., Murata, K. \& Kimura, A. (1983). Transformation of intact yeast cells treated with alkali cations. $J$ Bacteriol 153, 163-168.

Keppel, E. \& Schaller, H. C. (1991). A 33 kDa protein with sequence homology to the 'laminin binding protein' is associated with cytoskeleton in hydra and in mammalian cells. J Cell Science $\mathbf{1 0 0 ,}$ 789-797.

Kyte, J. \& Doolittle, R. F. (1982). A simple method for displaying the hydropathic character of a protein. J Mol Biol 157, 105-132.

Laemmli, U. K. (1970). Cleavage of structural proteins during the assembly of the head of bacteriophage T4. Nature 227, 680-685.

Lee, K. L., Buckley, M. R. \& Campbell, C. (1975). An amino acid liquid synthetic medium for development of mycelial and yeast forms of Candida albicans. Sabouraudia 13, 148-153.

López-Ribot, J. L., Casanova, M., Martinez, J. P. \& Sentandreu, R. (1991). Characterization of cell wall proteins of yeast and hydrophobic mycelial cells of Candida albicans. Infect Immun 59, 2324-2332.

López-Ribot, J. L., Casanova, M., Monteagudo, C., Sepúlveda, P. \& Martinez, J. P. (1994). Evidence for the presence of a highaffinity laminin receptor-like molecule in the surface of Candida albicans yeast cells. Infect Immun 62, 742-746.

López-Ribot, J. L., Monteagudo, C., Sepúlveda, P., Casanova, M., Martinez, J. P. \& Chaffin, W. L. (1996). Expression of the fibrinogen binding mannoprotein and the laminin receptor of Candida albicans in vitro and in infected tissues. FEMS Microbiol Lett 142, 117-122.

Mcllhinney, R. A. J. (1990). The fats of life: the importance and function of protein acylation. Trends Biochem Sci 15, 387-391.

Marcilla, A., Elorza, M. V., Mormeneo, S., Rico, H. \& Sentandreu, R. (1991). Candida albicans mycelial wall structure: supramolecular complexes released by Zymolyase, chitinase and $\beta$ mercaptoethanol. Arch Microbiol 155, 312-319.

Mecham, R. P. (1991). Receptors for laminin on mammalian cells. FASEB J 5, 2538-2546.

Moukadiri, I., Armero, J., Abad, A., Sentandreu, R. \& Zueco, J. (1997). Identification of a mannoprotein present in the inner layer of the cell wall of Saccharomyces cerevisiae. J Bacteriol 179, 2154-2162.

Narasimhan, S., Armstrong, M. Y. K., Rhee, K., Edman, J. C., Richards, F. F. \& Spicer, E. (1994). Gene for an extracellular matrix receptor protein from Pneumocystis carinii. Proc Natl Acad Sci USA 91, 7440-7444.

Odds, F. C. (1988). Candida and Candidosis. A Review and Bibliography, pp. 42-59. London: Baillière Tindall.

Ramón, A. M., Gil, M. R., Burgal, M., Sentandreu, R. \& Valentín, R. (1996). A novel cell wall protein specific to the mycelial form of Yarrowia lipolytica. Yeast 12, 1535-1548.

Ramón, A. M., Valentín, E., Maicas, S. \& Sentandreu, R. (1997). Expression of YWP1, a gene that codifies a specific Yarrowia lipolytica mycelial cell wall protein, in Saccharomyces cerevisiae. Fungal Genet Biol 22, 77-83.

Randez-Gil, F., Prieto, J. A., Murcia, A. \& Sanz, P. (1995). Construction of baker's yeast strains that secrete Aspergillus oryzae alpha-amylase and their use in bread making. J Cereal Sci 21, 185-193.

Rao, M. J. K. \& Argo, P. (1986). A conformational preference parameter to predict helices in integral membrane proteins. Biochim Biophys Acta 869, 197-214.

Raué, H. A., Mager, W. H. \& Planta, R. J. (1991). Structural and functional analysis of the yeast ribosomal proteins. In Guide to Yeast Genetics and Molecular Biology, pp. 453-477. Edited by C. Guthrie \& G. R. Fink. San Diego: Academic Press.

Rosenthal, E. T. \& Worderman, L. (1995). A protein similar to the $67 \mathrm{kDa}$ laminin binding protein and $\mathrm{p} 40$ is probably a component of the translational machinery in Urechis caupo oocytes and embryos. J Cell Sci 108, 245-256.

Sambrook, J., Fritsch, E. F. \& Maniatis, T. (1989). Molecular Cloning: a Laboratory Manual, 2nd edn. Cold Spring Harbor, NY: Cold Spring Harbor Laboratory.

Sanger, F., Nicklen, S. \& Coulson, A. R. (1977). DNA sequencing with chain-terminating inhibitors. Proc Natl Acad Sci USA 74, 5463-5467.

Sentandreu, M., Elorza, M. V., Valentín, E., Sentandreu, R. \& Gozalbo, D. (1995). Cloning of cDNAs coding for Candida albicans cell surface proteins. J Med Vet Mycol 33, 105-111.

Sentandreu, R., Elorza, M. V., Mormeneo, S., Sanjuán, R. \& Iranzo, M. (1993). Possible roles of mannoproteins in the construction of Candida albicans cell wall. In Dimorphic Fungi in Biology and Medicine, pp. 169-175. Edited by H. Vanden Bossche, F. Odds \& D. Kerndge. New York: Plenum.

Sherman, F. (1991). Getting started with yeast. In Guide to Yeast Genetics and Molecular Biology, pp. 3-21. Edited by C. Guthrie \& G. R. Fink. San Diego: Academic Press.

Towbin, H., Staehelin, T. \& Gordon, J. (1979). Electrophoretic 
transfer of proteins from polyacrylamide gels to nitrocellulose sheets: procedure and some applications. Proc Natl Acad Sci USA $76,4350-4354$.

Wool, I. G. (1996). Extraribosomal functions of ribosomal proteins. Trends Biol Sci 21, 164-165.

Woolford, J. L. \& Warner, J. R. (1991). The Molecular and Cellular Biology of the Yeast Saccharomyces: Genome Dynamics, Protein Synthesis and Energetics. Cold Spring Harbor, NY: Cold Spring Harbor Laboratory.
Yow, H., Wong, M. J., Chen, H. S., Lee, C., Steele, G. D. \& Chen L. B. (1988). Increased mRNA expression of a laminin-binding protein in human colon carcinoma: complete sequence of a fulllength cDNA encoding the protein. Proc Natl Acad Sci USA 85, 63946398.

Received 17 October 1997; revised 16 December 1997; accepted 24 December 1997. 